\title{
Lucha de los cabildos castellanos por su autonomía y libertad (1553-1555)
}

\author{
JoAquín GiL SANJUÁN *
}

\section{LA REFORMA DE LOS CABILDOS ECLESIÁSTICOS}

La historia de los cabildos se halla íntimamente unida a los bellos edificios de las catedrales y colegiatas, a cuyo servicio deben la razón de su existencia. Dichas corporaciones siempre han ocupado un lugar preeminente en la organización jerárquica de la Iglesia, a las que se les encomendaban funciones relevantes en el gobierno de las diócesis y, en la mayoría de los casos, proporcionaban los candidatos en los nombramientos episcopales.

Es, pues, sugestiva la tarea de aproximarse a esta institución eminente para correr el velo del pasado y poder contemplar su vida interna. Hay que arrancar de las postrimerías del siglo XII para comprender la profunda transformación que se operó en los cabildos de las catedrales, ya que en esta época se constituyeron en persona jurídica, independiente de la autoridad episcopal, por medio de privilegios de exención obtenidos de la Sede Apostólica. Después del siglo xIII, los canónigos trataron de atar y disminuir los poderes y derechos del nuevo obispo a través de las capitulaciones electorales. En el siglo XIV numerosos cabildos eran ya corporaciones autónomas provistas de constituciones propias ${ }^{1}$.

Los intereses económicos influyeron notablemente en la separación de los obispos y canónigos, ya que aquellos intentaban introducir a sus familiares en los cabildos, con la oposición tenaz de los prebendados, que tenían especial interés en no ver disminuidas sus rentas. Por este motivo,

Universidad de Málaga.

López Arévalo, J.R., Un cabildo catedral de la vieja Castilla, 1966, págs. 60-75. 
se dirigían a la Santa Sede al objeto de obtener toda clase de documentos para restringir el poder episcopal y obtener, por otra parte, la ampliación de sus propias facultades jurídicas de independencia, consiguiendo así plena autonomía con respecto a sus prelados.

Los cabildos llegaron a poseer amplias atribuciones jurisdiccionales, hasta el punto de considerarse totalmente exentos en materia de justicia civil y criminal. Poseían sus propios tribunales, cárceles y prisiones que, obviamente, se convertían en verdaderas fortalezas para proteger a los delincuentes del castigo episcopal o gubernamental. Como es de suponer, la justicia de los magistrados capitulares no pecaba de rigurosa, ya que juzgaban a sus propios compañeros $y$, en muchos casos, no eran estos jueces los que más brillaban por su conducta ejemplar ${ }^{2}$.

En esta autonomía hay que buscar el porqué de las numerosas diferencias entre obispos y cabildos que, con el tiempo, degenerarian en interminables litigios, haciendo necesaria la intervención de Roma. En esta separación y pugna se encuentra la causa de innumerables abusos, cuyo denominador común hay que buscarlo siempre en las exenciones de la jurisdicción episcopal, así como en los privilegios obtenidos de Roma, que acentuaban a su vez la división entre los capitulares y sus obispos. La relajación, fruto de la época del tránsito a los tiempos modernos, también llegó al interior de los claustros de las catedrales. Por otra parte, el alto concepto del honor les volvía muy susceptibles, hasta el punto de que cualquier nimiedad podía dar lugar a interminables pleitos. La libertad, conseguida a título de privilegio se convirtió en caldo de cultivo de numerosas controversias y colisiones de competencia jurídica ${ }^{3}$.

En la España del siglo XVı el número de cabildos giraba en torno a los 125. Menos de la mitad de ellos integraban el clero catedralicio, mientras los restantes pertenecían a las colegiatas, en las que no contabilizamos las de régimen señorial. Se puede calcular una cifra aproximada de 7.000 prebendados, entre dignidades, canónigos, racioneros y medio racioneros, el cincuenta por ciento de los cuales correspondía a las catedrales. A ellos se debe añadir un gran número de personas al servicio de los cabildos: capellanes, sacristanes, mayordomos, procuradores y un largo etcétera de servidores menores de difícil cuantificación, dada la diversidad

2 Fliche, A. y Martín, V., Histoire de l'Église, vol. 7, págs. 250 y sigs. López, N., "Don Luis de Acuña, el cabildo de Burgos y la reforma», Burgense, núm. 2 (1961), págs. 185 y sigs. GutiéRRez, C., Trento: un concilio para la unión (1550-1552). Madrid, 1981, vol. 3, págs. 240 y sigs.

Ibidem, pág. 246, donde se describe la situación moral de los cabildos exentos. 
existente en estas entidades capitulares. Los anteriores datos resaltan la importancia de este grupo social, verdadera elite del poder eclesiástico de la época ${ }^{4}$.

Desde el Concilio de Constanza, flotaba en el ambiente general de la Iglesia un profundo deseo de reforma y, así, como una suave brisa, por los cambios de presión atmosférica, puede llegar a convertirse en un fuerte viento irresistible, en el siglo xVI, los anhelos puros aislados de siglos anteriores, llegaron a transformarse en una fuerza arrolladora que desembocaría en dos tendencias opuestas: la Reforma originada por Lutero, Enrique VIII y Calvino, etc., y la Contrarreforma. Durante el siglo anterior se dieron diversos movimientos de regeneración dentro de la Iglesia Católica, hasta el punto de que el siglo xV puede llamarse «la edad de las reformas", porque fueron incontables las tentativas de renovación, algunas de ellas con éxito, como la Devoción Moderna, originada en los Países Bajos, y la creación de congregaciones de observancia dentro de las órdenes religiosas.

Sin embargo, no consta la existencia de tendencia alguna importante de signo reformador dentro de las corporaciones capitulares, donde abundaba la corrupción de sus miembros, y cuyo espíritu cristiano no estaba en consonancia con el esplendor de las bellas catedrales y los artísticos coros que las adornaban. Una canonjía, en la época a que hacemos referencia, llegó a ser carrera obligada de los hijos segundones de la nobleza, atraídos por las ricas prebendas, y meta fácil de conseguir desde que se exigió la limpieza de sangre para la admisión en los cabildos. Esta situación trajo consecuencias perniciosas para la vida cristiana de sus miembros, dado que muchos de ellos, especialmente los más significativos, habían abrazado el estado eclesiástico motivados por fines espurios $^{5}$.

\section{LA REFORMA TRIDENTINA DE LOS CABILDOS}

Antes de los inicios del concilio tridentino, los obispos, en sus memoriales de reforma, manifestaron sus decididos deseos de poner remedio

Este cálculo está confeccionado en un apoyo estadístico muy posterior a la época tridentina, pero de bastante fiabilidad, ya que no se habían producido cambios sustanciales en el ordenamiento de la institución eclesiástica publicada por J. Canga, en el Diccionario de Hacienda, BAE, vol. CCX. Cfr. Bennassar, B., La España del siglo de oro. Barcelona 1983, pág. 194.

5 Gelabert, J.E., «El Siglo de Oro. Economía y Sociedad», en Historia de España Planeta. Barcelona 1989, vol. V, pág. 310. 
a los abusos de sus capitulares, ya que, en la mayoría de los casos, habían sido testigos mudos de toda clase de desmanes, amordazados como estaban por determinados privilegios que les impedían actuar enérgicamente sobre quienes, teóricamente, deberían ser sus subordinados.

El Concilio de Trento, en su primera convocatoria (1545-47), aprobó el decreto cuarto de la sesión sexta, que afectaba de lleno a los cabildos catedrales. La redacción es intencionadamente confusa, debido a los encontrados pareceres sobre este tema, prestándose por ello a diversas interpretaciones. En realidad, se trataba de una concesión hecha por los legados a los obispos españoles ante la insistencia que mostraron al respecto. Aquellos reconocieron que sería origen de pleitos, pero no podían imaginar la cantidad de los que iban a surgir posteriormente, así como las consecuencias que traerían consigo cuando los algunos prelados castellanos tratasen de poner en práctica este decreto:

Capitula cathedralia et aliarum maiorum eclesiarum illorumque personae nullis exemptionibus, consuetudinibus, sententiis, iuramentis, concordis (quae tantum suos obligent auctores, non etiam succesores) tueri se possint, quominus a suis episcopis et aliis maioribus prelatis per se ipsos solos vel illis, quibus sibi videbitur, aiunctis, iuxta canonica sanctiones toties, quoties opus fuerit, visitari, corrigi et emendari, etiam auctoritate Apostolica, possint et valeant ${ }^{6}$.

Según la interpretación de los legados, en este canon no se trataba de una abolición completa de las exenciones, sino solamente de la facuitad dada a los obispos para corregir, en caso de delitos, a los capitulares, entendiéndose únicamente de los capítulos catedrales que no eran exentos a primaeva erectione o de tiempo inmemorial. Se estudiaron y midieron bien las palabras para no incluir a estos últimos. Fue una concesión que se hizo a los españoles para evitar el peligro que se cernía sobre la próxima sesión, en la que se temía una estruendosa derrota del proyecto oficial ${ }^{\text {? }}$.

En la segunda convocatoria conciliar (1551-52), los representantes españoles no consiguieron imponer su programa reformístico, cuyo objetivo principal consistía en restaurar la disciplina eclesiástica por medio de la

6 Concilium Tridentum, Diariorum, Actorum, Epistolarum, Tractatuum (CT), Friburgo, 1901 y sigs. vol V, págs. 804 y 816 y vol X, págs. 13 y 816, Ed. Societas Goerresiana. Jedin, H., Storia del concilio di Trento. Brescia, Ed. Morcelliana, vol. II, págs. 394 y sigs. Cfr. TEJAdA, J., Colección de cánones de todos los concilios de la Iglesia de España y América. Madrid 1859-63, vol. IV, pág. 77.

CT, op. cit, pág. 86. Cfr. GutiéRrez, C., op. cit, págs $268,276,284,316,346$. 
asunción plena de la responsabilidad episcopal con respecto a todos sus eclesiásticos y, particularmente, sobre los beneficiados capitulares. No es de extrañar, pues, que el grupo de conciliares españoles se fueran familiarizando con la idea de intentar la reforma a su modo, en el ámbito nacional, como ya había sugerido algún obispo en reuniones privadas ${ }^{8}$.

Los cabildos, en vista de la tormenta que se estaba fraguando contra ellos en la asamblea conciliar, intentaron acudir a ésta con la finalidad de defender sus privilegios y exenciones; pero, el Consejo Real, por deseos de Carlos V, no sólo les prohibió mandar a sus representantes a Trento, sino que impidió el enviar memoriales para exponer sus razonamientos y quejas sobre esta cuestión, tan vital para su autonomía y libertad.

\section{INTERVENCIÓN DEL CONSEJO REAL}

Las controversias jurisdiccionales entre los cabildos y sus obispos, apoyados por el gobierno, se desarrollaron durante cuatro años (155356), interfiriendo en el clima prebélico del interregno de Carlos $V$ a Felipe II, que desembocó en la Ilamada por García-Villoslada «absurda guerra» protagonizada por el monarca español y el papa Paulo IV ${ }^{9}$.

Los cabildos exentos, prácticamente, habían robustecido su situación jurídica en las dos primeras convocatorias conciliares, pues de la terminología del único decreto reformatorio, aprobado el 25 de febrero de 1547, se desprendía tácitamente el reconocimiento de sus privilegios y de su dependencia directa de la Santa Sede, ya que a los obispos se les consideraba simples delegados de ella.

Existía el peligro, en la aplicación de los decretos conciliares, de que los obispos se apropiasen de la interpretación de los mismos, sin consultar previamente a Roma. Efectivamente, algunos prelados castellanos intentaron aplicar con propia autoridad el decreto de visita y corrección a sus capitulares, animados y amonestados por la autoridad civil ${ }^{10}$.

Según «El parecer de Melchor Cano y Domingo Soto sobre el concilio de Trento, 1555», el Consejo Real juzgaba que los decretos conciliares

8 Rogger, I., Le Nazioni al Concilio di Trento durante la sua epoca imperiale. Roma 1952, págs. 217 y sigs.

9 GarCíA-VILLOSLADA, R., «Felipe II y la Contrarreforma Católica», en Historia de la Iglesia en España, vol. lli-2. . Madrid 1980, págs. 38-46.

${ }_{10} \mathrm{CT}, \mathrm{XI}$, pág. 95; X, págs. 791 y 826. Radrizzani, J.F., Papa y obispos en la potestad de la jurisdicción, según el pensamiento de Vitoria. Roma 1967, págs. 252-74. 
eran necesarios para el buen gobierno de la Iglesia de España, en la que, debido a las muchas exenciones de los cabildos, la justicia y la disciplina eclesiástica padecía detrimento. Por otra parte, ante la pasividad de Roma de no ordenar la ejecución de dichos decretos, competía al rey proteger y defender la Iglesia en su reino $y$, atendiendo a que en el concilio se urgió a los príncipes al cumplimiento de lo establecido en el mismo, el Consejo Real encargó a todos los obispos que guardasen lo preceptuado en la asamblea conciliar. Por este motivo, se envió a cada obispo la real cédula de Felipe II, a la sazón Príncipe Regente, fechada el 3 de octubre de 1553, en la que se lee lo siguiente:

«...os encargo y mando que todo lo constituido y ordenado en dicho Concilio Tridentino hagáis cumplir y executar en vuestra iglesia y diócesis, y no consintáis que por manera alguna se venga contra el dicho concilio ni contra parte de lo en él mandado y proveido, pues es tan propio de vuestro cargo y solicitud...” ${ }^{11}$.

Junto con esta real cédula, el Consejo expidió un mandamiento a todos los gobernadores y justicias de España con la finalidad de que facilitasen la tarea reformatoria a los obispos, evitando asi toda la labor obstruccionista que pudieran presentar los prebendados. Es de notar cómo la actuación del Consejo Real fue realizada a instancias de algunos obispos, que le presionaron para obtener provisiones reales con objeto de garantizar el cumplimiento de lo establecido por Trento ${ }^{12}$.

Amonestados y animados muchos obispos por las reales cédulas, inteitaron aplicar con propia autoridad el decreto de visita y corrección a sus cabildos a finales de 1553, a pesar de que algunos de éstos presentaban letras apostólicas de exención, alegando depender directamente de la jurisdicción papal y, por lo tanto, no se consideraban obligados a acatar dicho decreto. Los prelados estaban decididos a dar el asalto definitivo a la inexpugnable fortaleza de los privilegios de los capitulares para someterlos, después de los reiterados y fracasados intentos en una lucha ya vieja.

El Consejo Real dio otra provisión el 6 de diciembre de 1553 a los gobernadores y justicias del reino, donde amenazaba con la utilización del placet regio, uno de los instrumentos más eficaces de la política regalista de los monarcas españoles:

11 Caballero, F., "Vida de Melchor Cano», en Conguenses ilustres, vol. II. Madrid 1871, págs. 489-99; vid. págs. 91-92.

12 Fernández Alvarez, M., «El siglo xvi. Economía. Sociedad. instituciones», en Historia de España Menéndez Pidal. Madrid 1990, vol. XIX, págs. 539-53. 


\begin{abstract}
...Porque vos mandamos que si algunas bulas, o letras apostólicas, o citaciones, o inhibiciones, o exenciones se han traído y presentado, o traxeren y presentaren por cualesquier persona sobre los susodicho, en derogación de lo ansí proveído e mandado en el sacro concilio. Habiéndose suplicado o suplicándose dellas por parte del dicho nuestro fiscal, para nuestro muy sancto padre, y haciéndose sobrello los autos y diligencias que convenga, no consintáis usar della, ni que por virtud dellas se hagan autos, y las enviéis originalmente ante los de nuestro Consejo, con todos los autos por virtud dellas fechos, para que por ellos vistas si fueren tales que se deban cumplir, y si no, se informe dello a su Sanctidad, para que mejor informado de la verdad, lo mande ver y remediar como convenga ${ }^{13}$.
\end{abstract}

Melchor Cano justificó el proceder de Felipe II y sus consejeros, alegando que la actuación del Príncipe con sus reales cédulas y mandatos es justa, pues era de suponer que la Curia Romana aceptase el cumplimiento de los decretos conciliares. El rey, como protector de la Iglesia de su reino, al comprobar la dilación por parte de Roma en hacerlos ejecutar, obró bien; aunque la palabra «mandamos» no le parecía jurídica, al tratarse de obispos y cabildos, sujetos a la jurisdicción eclesiástica, siendo preferible que se hubiese utilizado la expresión «exhortamos y amonestamos».

En cuanto al uso de placet regio, por el que la justicia civil impedía intimar letras apostólica sin que previamente hubiesen sido censuradas por el Consejo Real, el teólogo dominico cree que el rey y sus ministros pueden interceptar los documentos pontificios, con tal de que no sea para retenerlos perpetuamente, sino para comprobar que no contienen evidente fuerza, poniendo de manifiesto de esta manera una teoría muy próxima al regalismo. Justo es reconocer que los abusos de la Curia Romana provocaban con frecuencia la intervención de los príncipes en el ámbito religioso, muy de acuerdo con el principio cuius regio, eius religio, que imperaba en la época de la Reforma.

El enfrentamiento de los cabildos contra sus obispos y el Consejo Real fue la consecuencia de las contrastadas posturas de ambas partes. Los capitulares gozaban de gran autonomía, amparada en su teórica dependencia de Roma, mientras que los prelados deseaban el total control de su diócesis, recabando el apoyo real para suprimir privilegios y exenciones, sin percatarse que con ello se robustecía el autoritarismo del monarca.

13 Ibidem. 
La Corona poseía, a partir del reinado de Carlos I, el privilegio de presentación de los candidatos a la dignidad episcopal, cuyo nombramiento, como es lógico, recaía en personas adictas a su causa. A través del fortalecimiento del poder de los prelados se ambicionaba la sumisión de los cabildos, ensanchando con ello el dominio centralizador del Estado moderno.

\section{AGUSTÍN DE CASTRILLO, ABANDERADO DE LA CAUSA DE LOS CABILDOS}

Los cabildos conocían muy bien la disposición de los obispos españoles, que pretendían su completa sumisión, amparados en lo decretado en Trento. Según transcurrían los acontecimientos, tuvieron que apresurarse para defenderse tenazmente de sus obispos. Su gran acierto fue escoger Roma como campo de batalla en la contienda que se avecinaba, sin duda alguna, era el sitio ideal para desplegar todas sus armas, pues por la experiencia sabían que la tenían perdida en la Península.

El primer paso que dieron fue constituir una junta de cabildos en Valladolid, probablemente en 1553, cuando comprobaron la firme decisión de los obispos y del Consejo Real en llevar a la práctica lo decretado en Trento; pero, hasta bien entrado el año 1554, no dieron muestra de actuar con arreglo a un plan establecido.

Convencidos de que Roma era el lugar idóneo para la defensa de sus privilegios, allí comisionaron a sus representantes, seleccionando personas capacitadas para desempeñar tan difícil misión. Entre todos, destacó notablemente Agustín de Castrillo, canónigo burgalés, por su habilidad, tesón y, especialmente, por la audacia que demostró al medir sus fuerzas con a los obispos, fuertemente respaldados por el poderoso Consejo Real, que seguía las directrices marcadas por Carlos I, Felipe II y la Princesa doña Juana, dada la situación de interregno por la que atravesaba España en aquellos años.

Se tienen noticias de una primera estancia de Castrillo en Roma durante 1543, como representante de beneficiados burgaleses. Allí contactó con personajes influyentes de la curia romana que, años más tarde, serán sus poderosos amigos y áliados en la defensa de la exención de los cabildos. Entre ellos sobresalen los nombres de Cicada, Ricci y Puteo, que más tarde llegaron a vestii la púrpura cardenalicia y desempeñaron altos cargos en la corte pontificia. Su segunda estancia probablemente se inició a finales de 1552.

Castrillo, en la correspondencia con su cabildo, se nos muestra como avispado observador de ese mundillo complicado que ha sido siempre la 
curia romana. Carta tras carta insiste con curiosa machaconería en los puntos principales de su difícil misión, y su estilo epistolar salva la monotonía con gracejo inimitable en el manejo de las expresiones populares, que admirablemente reflejan complicadas situaciones.

Vemos como en un momento determinado porque «estaba caldo el hierro era bien batirle», «tener las manos en la masa», "no sean escasos de papel y tinta». Frases gráficas que sus compañeros capitulares de España comprendían a la perfección por su oportunidad y sencillez tan castellana.

El canónigo Castrillo era cronista de algo importante: la pugna entre los cabildos y sus prelados. Sabe el valor de cuanto puede ayudar a su misión y, de una manera especial, el valor del dinero que pedía constantemente. Habla de propinas ya que para "guardar su joya», refiriéndose a la libertad de los capitulares, merece la pena que «se aventure y gaste lo que se aventurare».

Otras veces, para resaltar sus dificultades, vuelve a la frase gráfica, y así sabemos que andaba ya «junto a los cuernos del toro». Avanza la gestión, todo parece marchar bien, pero aún falta un pequeño esfuerzo para que «después de la muestra de tan buena flor no se nos hiele el fruto».

Describe su habilidad para tratar con quienes «pueden hacer bien en este negocio, que los tengo tan contentos con no espender un real como si echase a millares los escudos». Sabe sopesar todo, «diligencia en el hacer» $y$ "dineros", pero reconoce que «lo uno sin lo otro no vale nada».

Lamenta que el cabildo no se haga eco de sus consejos: «han hecho tan poco caso que no me queda más del arrepentimiento de lo mucho que he trabajado empleando mi favor y servidumbre particular por quien va dando muestra de no conocerlo». Pide ayuda material porque «para conducir este negocio no sólo basta con decir misas ......, sino con obras y regalos que cuestan»; el mismo es consciente de que está obligado «con tantas promesas que si no las pago no saldré de deuda, sino con vergüenza mía y daño del negocio».

Sería interminable la cita de frases expresivas ya que abundan sobremanera en sus cartas, en cuyo estilo resalta la sencillez.

Actúa como cronista de cuanto ve y oye, y solamente echa mano de la pincelada pintoresca de sus refranes y locuciones populares para lograr introducir a quienes leían sus cartas en el clima de cardenales, prelados y procuradores que se movían junto al papa en torno al asunto central que llevó a Castrillo a Roma: la lucha jurisdiccional entre obispos y cabildos. 
El valor histórico de la correspondencia es indudable, aunque es necesario despojar de apasionamiento a algunas de sus afirmaciones. Su misma espontaneidad que, a veces nos hace caer en datos y situaciones que recogen admirablemente el ambiente de la época, le traiciona y ciega para comprender las razones de la parte adversa ${ }^{14}$.

Como es lógico, Castrillo trabajaba ante todo para su iglesia: «yo hago lo que puedo, porque como nascí libre en esa iglesia, sentiría gravemente el yugo". Constantemente da ánimos a los suyos en la lucha declarada entre obispos capitulares, cuya enseña será la libertad.

\section{LA REBELIÓN DE LOS CABILDOS CASTELLANOS Y SU REPRESIÓN POR EL CONSEJO REAL}

El primer triunfo que se anotó Castrillo fue una citación inhibitoria de la Rota romana, de 21 de noviembre de 1553, al cardenal Mendoza ordenándole que abstuviese de todo acto contrario a la jurisdicción capitular, bajo severas penas. Documentos semejantes fueron enviados a varios cabildos castellanos, constituyendo una auténtica declaración de guerra entre los capitulares y sus obispos al fijarlos públicamente en las puertas de algunas catedrales ${ }^{15}$.

La inhibición rotal enviada por Castrillo fue el primer chispazo de la tormenta, presagiada ya desde los comienzos del concilio, que descargó toda su furia en el trienio de 1553 a 1555 . No tardaron los capitulares burgaleses en dar cumplida ejecución del documento, fijándolo ad valvas en la catedral. El Consejo Real prohibió el uso de la sentencia rotal, ordenando que fuera llevada a la Corte, donde detuvieron al deán y capiscol durante muchos días ${ }^{16}$.

Escena semejantes ocurrieron en otras catedrales de la geografía española ${ }^{17}$. Don Juan Bernal Díaz de Luco, obispo de Calahorra la Calzada

14 Archivo de la Catedral de Burgos (ACB), Cartas misivas de Roma desde el año 1550 a 1556, vol. 4. Para el tema de la pugra entre cabildos y prelados, interesan particularmente 36 carta escritas por Castrillo durante los años 1555-56, todas ellas de capital importancia para el estudio de las difíciles relaciones entre la Corona española y el papado. Con estas cartas también se encuentran diversos documentos relacionados con el tema.

15 Ibidem, carta de 20 de enero de 1554; carta de la Congregación de Cabildos de Valladolid, 18 de marzo de 1554. Para los orígenes de los conflictos entre capitulares y obispo, Cfr. Gutiérrez, C., Op. Cit., pág. 239.

16 ACB, libro 48, fols. 185 al 191 , notificación notarial de la inhibición de la Rota.

17 El material existente en los archivos capitulares acerca de la lucha de los prebendados es abundante. Sobre este tema, Cfr. Serrano, L., "Anotación al tema: Paulo IV y España", His- 
y asistente a las dos primeras etapas conciliares, personaje destacado por su ciencia y rigorismo, al intentar la aplicación de los decretos conciliares a sus capitulares, se enfrentó con la resistencia de éstos, que alegaban la concordia existente con el prelado. Como en otras partes, fijaron la sentencia de inhibición y citación procedente de Roma en las puertas del templo catedralicio. El obispo ayudado por la justicia civil arrancó la sentencia y ordenó, bajo graves penas, que fuera exhibida la documentación en la Corte, desde donde el gobierno emitió provisiones de apoyo para el cumplimiento de lo acordado en el concilio ${ }^{18}$.

En Zamora, el obispo Antonio del Águila, también asistente a la segunda etapa tridentina, y que además era consejero real, procedió contra su cabildo, acudiendo para ello a la ayuda del brazo secular. La justicia civil prendió al chantre por no mostrar la sentencia de la Rota. Fueron encarcelados cuatro canónigos, imponiéndoles el obispo una multa de quinientos ducados, que fueron cargados a la cuenta de la mesa capitular. El corregidor envió los presos a la Corte y los puso en libertad en el mes de marzo de 1554. El Consejo Real tramitó provisiones al obispo y corregidor para hacer guardar al pie de la letra lo establecido por el concilio, con amenazas de multas y destierro a los que contraviniesen esta órdenes ${ }^{19}$.

El obispo de Astorga Pedro de Acuña, asistente también a la segunda convocatoria tridentina, mandó prender a cuatro dignidades y un canónigo, porque habían conseguido de Roma documentación inhibitoria. El documento fijado ad valvas fue remitido al Consejo, que envió al alcalde fijado de alzadas a petición del fiscal del rey para decomisar las sentencias romanas y realizar un informe sobre la posible utilización de las mismas, con potestad para encarcelar, desterrar y multar a todos los que incumplieran lo ordenado ${ }^{20}$.

Cuando el provisor de Sevilla pretendió visitar el cabildo, los canónigos consiguieron igualmente inhibición y citación de la Rota, para exigir que

pania, núm. 3 (1943), págs. 293-325; CercedA, F., "El litigio de los cabildos españoles y sus repercusiones en las relaciones con Roma», Razón y Fe, núm. 13 (1944), págs. 215-34; GoN̄I, J., Los navarros en el Concilio de Trento y la reforma tridentina en al diócesis de Pamplona. Pamplona 1947, págs. 151 y sigs.; MARíN, T., «Primeras reacciones tridentinas", Hispania Sacra núm. 1 (1948), págs. 325-349; LóPEZ, N., "El cardenal Mendoza y la reforma tridentina», Hispania Sacra, núm. 16 (1963), págs. 61-137.

is Marín, T., op cit., págs 333 y sigs. ACB carta de la Congregación de Cabildos de Valiadolid a los procuradores de Roma, 18 de marzo de 1554.

19 ACB, Memorial de la Congregación de Cabildos a los procuradores de Roma, 18 de marzo de 1554; Cfr. CercedA, F., op. cit., págs. 217-19.

20 Ibidem. 
fuese el propio obispo el que girase la visita, conforme a lo establecido en los decretos reformatorios, y así mismo que éste residiese en la diócesis. La documentación fue remitida a Valladolid, mientras que se detuvo a cuatro canónigos, que fueron enviados también a la Corte. Es más, dicho provisor prendió al canónigo que había dado un golpe a un racionero, junto con el juez que realizó la información sobre el suceso para enviarla a Roma. El canónigo cayó enfermo y murió en prisión. Otra de las tropelías del provisor fue el mandar descerrajar las cerraduras del coro para dar posesión a un intruso, realizando así, con la excusa de la aplicación del concilio, una serie de agravios y violencias al cabildo ${ }^{21}$.

El obispo de León, Fernández Temiño, se apoderó de una concordia que poseía el cabildo, previamente estipulada bajo juramento con el prelado, habiendo sido aprobada por Roma y confirmada por el monarca. Tuvieron lugar varias prisiones de canónigos, a la vez que el Consejo Real remitió la causa al obispo para que la aplicara conforme a los decretos conciliares ${ }^{22}$.

El obispo de Oviedo, otro de los asistentes al concilio, tuvo "asonadas" con su cabildos, y estuvo pendiente de lo que sucedía en otras iglesias para obrar consecuentemente del mismo modo en la suya ${ }^{23}$.

Las violentas reacciones de los obispos con sus capitulares se recogieron en un escrito de la Congregación de los Cabildos, constituida en Valladolid para la defensa de los derechos y privilegios de los cabildos de las catedrales, que posteriormente fue enviado a sus procuradores en Roma. La redacción estuvo a cargo de los diputados capitulares que habían sufrido los atropellos por parte de sus obispos. Posteriormente, se sumaron otros representantes de distintas provincias españolas. La finalidad de esta junta fue la de formar un frente común y defender sus intereses ante la curia pontificia. ${ }^{24}$.

Los cabildos, en su apelación a Roma, hacen hincapié en el hecho de que no se les permitió ir a Trento a defender su causa y, por otra parte, ponen de manifiesto "que las iglesias que el prelado no molesta, el Consejo no las fastidia ni tiene cuenta con ellas". Una de las acusaciones más graves de los capitulares contra sus obispos era: «La solicitud de los prelados en no residir en sus iglesias y hacer su oficio sin ser señores, y que su apelación nunca allá llegue, ni inhibitoria nos valga».

21 Ibidem.

22 Ibidem.

23 Ibidem; Cfr. Serrano, L., op. cit., pág. 297.

24 ACB, Memorial de la Congregación de Cabildos de Valladolid, 18 de marzo de 1554. 
No iban tan descaminados los cabildos cuando achacaban a sus prelados todos estos abusos, pues está demostrado el interés de los obispos españoles en rescatar los poderes que la centralización romana le había arrebatado en los últimos siglos. Es más, los españoles querían zanjar esta cuestión de una vez por todas con la declaración del derecho divino de la residencia, aunque estas ansias parecian más bien de tipo práctico que teórico. No era éste el parecer de los canónigos, quienes mostraron gran sagacidad para atacar a los obispos en su punto flaco: «Es codicia dellos y hacerse señores, más que çelo de buena gobernación» ${ }^{25}$.

El horizonte que se presentaba a los cabildos era muy oscuro, según se desprende de sus reclamaciones:

«...y dar a entender a su Santidad como por el suelo se trata acá de la libertad eclesiástica, y está ya tan en lo último este negocio que convendrá dejar las iglesias y el reino o obedesçer el concilio de Trento» ${ }^{26}$.

\section{ROMA, NUEVO ESCENARIO DE LA CONTIENDA}

El 16 de febrero de 1554, el cardenal Cicada comunicó a Castrillo que el pontífice estaba decidido a tomar cartas en el asunto. Efectivamente, el 27 de febrero era expedido un breve destinado a Leonardo de Marini, nuncio de España. Por la fecha y el contenido del mismo, no es probable que en Roma se tuvieran noticias de las tropelías causadas a los capitulares celosos de su privilegiada condición de autonomía con respecto a sus prelados. Su dependencia directa de Roma les garantizaba esta situación, dada la lejanía y el escaso control ejercido desde la capital de la cristiandad. Julio III expresaba en el citado breve su conocimiento de las controversias jurisdiccionales surgidas en España sobre la interpretación de los decretos conciliares, que había llevado a los obispos a infringir e incluso suprimir inmunidades y exenciones introducidas por justas causas o en la misma erección de las iglesias, siendo posteriormente confirmadas por el uso y posesión de tiempo inmemorial. El pontífice ordenó al nuncio que escuchase a ambas partes y remitiese la información conseguida al respecto ${ }^{27}$.

25 Ibidem.

26 Ibidem.

27 Archivio Segreto Vaticano (ASV), armario 41, tomo 70, fol. 197, minuta del breve de 27 de febrero de 1554. Cfr. ACB, cartas misivas, carta de Castrillo al cabildo, 16 de febrero de 1554. 
Castrillo envió el breve por el camino más seguro, el de Lyon, para evitar que la correspondencia cayese en manos de la justicia real como ocurría frecuentemente. El día 4 de marzo salía el documento para España por conducto de Lope de Gallo. En el documento se ve la mano oculta de Castrillo, quien sin embargo no hizo alarde del triunfo ${ }^{28}$.

Esta lucha entre obispos y cabildos se iba canalizando a través de Burgos, a cuyo cabildo confiaba el nuncio sus despachos con destino a Roma. El asunto era delicado y los capitulares sabían que podían incurrir en las iras del todopoderoso Consejo Real. El mismo Castrillo, desde Roma, veía este peligro, recordando a sus compañeros cuáles eran las costumbres en caso de pleito con los prelados:

"Recuérdome que cuando otras veces le han sucedido a vuestra mercedes diferencias y lites con prelados siempre han hecho cierto estatuto y obligación de relevar indemne, etc. al que por esto padeçiere y, pues por mandato de vuestras mercedes yo ando ya junto a los cuernos del toro, les suplico que, si no estoy dentro de la cofradía, me metan... ${ }^{29}$ ".

Roma, mientras se esperaban los resultados del primer breve, se mostró conciliadora y, aprovechando la partida de un gentil hombre portugués, envió un despacho para el nuncio, por medio del cual se le concedían facultades para visitar las iglesias exentas, bien de forma personal o por procurador. Fue este período de relativa tranquilidad una especie de tregua, en la que Roma aguardaba el acatamiento de los obispos y que se abstuviesen de realizar intervenciones arbitrarias perjudiciales a la jurisdicción de los cabildos exentos.

Los obispos españoles, en réplica a la actividad de sus capitulares, también se congregaron en Valladolid, con el beneplácito del Consejo Real. El objetivo de esta asamblea, reunida a principios de 1554 , no podía ser otro que el de aplicar los decretos tridentinos en sus respectivas diócesis, para cuya ejecución solicitaron la ayuda del brazo secular. Resultado de la misma fueron las fuertes presiones ejercidas en la curia romana, hasta el punto de que en algunos dicasterios no querían tramitar documentos sin la licencia expresa de la Comisión de Reforma ${ }^{30}$.

Por su parte, la Congregación de Cabildos de Valladolid comenzaba a dar señales de vida con un memorial, escrito el 18 de marzo, donde

\footnotetext{
28 Ibidem, carta de 17 de marzo de 1554. Los despachos urgentes eran enviados por medio de correos propios o especiales, en ambos casos resultaba caro el porte. El envío de la carta y el breve costó hasta Lyon 50 ducados.

29 Ibidem, cartas de 10 a 16 de febrero de 1554 .

so Ibidem, cartas de 3 y 9 de junio de 1554.
} 
se recogían todas las penalidades sufridas por los cabildos castellanos. En mayo, dicha junta remitió una carta a Castrillo con instrucciones concretas sobre el modo de proceder en este asunto, recomendando que cada iglesia agraviada interpusiese recursos individualizados ante la Rota en los asuntos particulares; pero en lo concerniente al bien general de todos, serían Castrillo y los prebendados de Astorga los encargados de gestionar el remedio universal para todos los cabildos afectados por el ataque jurisdiccional de los obispos. Confían, a su vez, a Castrillo el liderazgo para que encauce el negocio de la manera que considere más oportuna, animándole a que con toda solicitud y diligencia prosiga en la empresa iniciada. Advierten que, aunque las iglesias pretenden diversos derechos de jurisdicción, todas desean el mismo objetivo: independencia y libertad con respecto a sus propios obispos ${ }^{31}$.

Castrillo siguió fielmente las instrucciones de sus superiores y, con renovado ímpetu, continuó en sus intrigantes actividades, apoyándose cada vez más en los cardenales Cicada y Ricci. Esta último era el dignatario más interesado por la causa de los cabildos. Hércules Severoli fue nombrado procurador general de la junta vallisoletana, y a él debian recabar los capitulares asesoramiento jurídico cuando lo necesitasen.

Paradójicamente, en España no se mostraba tan febril entusiasmo como el del prebendado burgalés, quien, presa de impaciencia, recrimina la lentitud en comunicarle los resultados del breve. Hasta el mes de junio no se tuvo noticia de lo acaecido en Castilla, donde la cosas no iban bien para los capitulares, debido a que de nuevo el Consejo Real había impedido, por prescripción del Príncipe Regente, lo ordenado en el documento pontificio, recurriendo incluso a la práctica regalista de la retención de bulas:

...La solicitud de los prelados es no residir en sus iglesias y hacer su oficio, sino de ser señores, y que apelación nunca allá llegue, ni inhibitoria nos valga, pues tienen los del Consejo tomadas las de Sevilla, Astorga, Calahorra y la Calçada; y el canónigo de Zamora, que tenían en su poder allí, se fue a Portugal, porque a él y allá no le prendiesen y llevasen al Consejo los oidores del cual. No obstante el breve venido, de cada hora proceden en su estilo de tomar y embiar provisiones sobrello, como de presente embían a León, y a Calahorra, y a Pamplona y a otra iglesias, prendiendo dignidades y canónigos la justicia seglar y entregándolos a los obispos sólo sobre este caso, sin haber hecho otro delito o desacato por medio. Y así, a las iglesias perseguidas no les vale ni les dexan usar de remedio que de allá venga ${ }^{32}$.

\footnotetext{
${ }_{31}$ Ibidem, carta de los diputados de la Congregación de Cabildos de Valladolid a Agustín de Castrillo, 4 de mayo de 1554 .

32 Ibidem.
} 


\section{VICTORIA FRUSTRADA DE LOS CABILDOS}

Castrillo, al comprobar el escaso resultado del breve, vuelve a la carga con los diputados de la reforma, exigiendo una solución rápida favorable a los cabildos. En caso contrario, amenaza con un entendimiento directo entre capitulares y prelados, con asentimiento de los consejeros reales. Muy eficaces fueron éstas y otras amenazas semejantes, pues con toda rapidez, por mandato del papa, se reunieron en congregación los cardenales. Fueron propuestas dos soluciones: la primera consistía en una nueva bula en tono amenazante, que se llevó a cabo en el mes de agosto; la segunda, podrían ser una declaración oficial del papa sobre la sesión sexta del concilio. La prematura muerte de Julio III impidió que se publicase un documento en sentido favorable a los cabildos, con ello quedaba abortada esta segunda y definitiva vía.

La escasez de recursos económicos de los capitulares constituía una seria dificultad para encontrar valedores en la venal curia romana. Castrillo ya no sabía a quien dirigirse, después de haber empeñado su palabra con toda clase de promesas sin poder satisfacer los ofrecimientos hechos. Conocedor de la eficacia del dinero y de los regalos, convocó a sus compañeros procuradores para celebrar una junta extraordinaria en casa de Severoli. En ella se acordó despachar un correo propio a España para recabar un crédito de 2.000 ducados, a fin de reavivar la negociación y contrarrestar la poderosa influencia de los obispos, que por entonces desplegaban una actividad inusitada, sin olvidar tampoco los ingredientes crematísticos.

El 12 de septiembre, Agustín de Castrillo, rebosante de alegría, comunicaba a su cabildo y a la junta de Valladolid el envío de dos breves, que para él significaban la victoria de los capitulares en el pleito jurisdiccional:

"a la hora presente estoy el más contento del mundo por pensar que he açertado a servir a vuestra mercedes y a todos esos señores de la congregación tan copiosamente, como vuestras mercedes, de la dicha letra, y breves y instrucciones que aquí van, podrán colegir» ${ }^{33}$.

Efectivamente, podía sentirse orgulloso con su triunfo, pues el pontífice había decidido actuar con energía en este vidrioso asunto, mostrándose severo en el breve dirigido a los prelados y algo más suave en el destinado

33 Ibidem, carta de Castrillo al cabildo de Burgos, 122 de septiembre de 1554. 
al Consejo Real. El canónigo burgalés envió 36 copias de ambos, así como las instrucciones precisas para obtener los mejores resultados. Encarecidamente recomienda a sus compañeros burgaleses que mandasen con urgencia a Valladolid la documentación destinada al nuncio, si no querían incurrir en desacato al mismo y, por lo tanto, también al papa.

Por instrucciones de sus protectores romanos, en el mismo correo, dirigió Castrillo una carta al nuncio con un interesante contenido, porque en ella se ve la presión a la que fue sometido desde Roma el representante papal de una manera muy poco diplomática, según el comentario que hizo a sus compañeros de Burgos:

«Aunque parece que la carta que yo escribo al señor Nunçio va algo insolente, no es sin misterio, y así tengo orden de escribir por mandato de quien lo puede hacer, y él lo entenderá mejor que vuestras mercedes, porque sabe él por qué lo digo» ${ }^{34}$.

En el breve dirigido a los obispos se explican los motivos de la intervención pontificia, basada en el atentado que suponía contra la libertad y autoridad del sumo pontífice, con ocasión de interpretar y aplicar los decretos conciliares. Según el documento, los jueces seculares, instigados por los obispos, detuvieron, encarcelaron e infligieron diversas penas a los que presentaban inhibiciones de la Rota. El papa, en consecuencia, revocaba todo lo hecho después de las apelaciones interpuestas por los cabildos ante los tribunales romanos. El breve incluía un monitorio contra los prelados para que, en el plazo de seis días, y bajo la pena de suspensión a divinis, relajen las penas impuestas y pongan en libertad a los encarcelados. Tajantemente prohíbe que en el futuro hagan uso de las provisiones emanadas del Consejo Real ${ }^{35}$.

En el breve dirigido al Consejo Real se hace constar que los asesores regios, por las provisiones hechas en perjuicio de la autoridad apostólica, podrían ser declarados incursos en censuras canónicas; pero, en deferencia al Emperador y al Príncipe, se suspendían todas ellas esperando que acataran lo ordenado.

Junto con los breves iban las instrucciones para la ejecución de los mismos, escritas por el cardenal del Monte. En lo referente al Consejo Real, debería hacerse prudentemente:

\footnotetext{
${ }^{34}$ Ibidem, copia de la carta de Castrilto al nuncio de España, 12 de septiembre de 1554; Cfr. la carta dirigida al cabildo de Burgos en la misma fecha.

${ }_{35}$ ASV, armario 41, libro 71, fols. 439 y sigs. Cfr. Caballero, op. cit., vol. 2, págs. 491 y sigs.
} 
"sensa que che le consiglieri se ne possino chiamar offisi, nondimeno su Santitá recorda chel lo poterebbe mostrarlo prima privatamente al capo, volemo dir Presidente del Conseglio, e farlo capire che 'I breve non ha in se alcuna nuova provisione, ma solamente un ammonitione di quanto dispongano i sacri canoni» ${ }^{36}$.

Los breves debieron llegar a Burgos sobre el 5 de octubre, pues en ese día escribieron a Castrillo el acuse de recibo. El nuncio recibió la documentación dos días después. Los burgaleses fijaron por la noche varias copias auténticas en lugares patentes de la ciudad. En Zamora observaron un proceder idéntico. Esta actitud ocasionó grandes contrariedades al nuncio, de las que se lamentó amargamente, y entorpeció a su vez la marcha del negocio al ofrecer motivos de irritación a los miembros del Consejo.

En cuanto al breve dirigido al Consejo Real, el nuncio lo intimó según las instrucciones recibidas. El 14 de octubre entregó al presidente una copia a la vez que le mostraba el original, a pesar de saber que ya disponía de otra copia auténtica diestramente agenciada por otras vías. A la queja de los consejeros por la dureza de los breves, respondió el representante pontificio que el papa tuvo más respeto con el rey de España que los consejeros con su Santidad. Afortunadamente la princesa doña Juana procuró calmar los ánimos de los asesores regios.

Los Acontecimientos se sucedían con tal rapidez que las noticias de los mismos se entrecruzaban en el camino. Antes de saberse los efectos de los breves, se tuvieron referencias procedentes de España acerca del sometimiento de algunos cabildos a sus obispos consintiendo la temible visita, incluso con juramento de permitirla en un futuro; por este motivo Castrillo procuró la expedición de otro nuevo breve, mediante el que se liberaba a los capitulares de esta obligación.

No obstante los severos documentos pontificios, a primeros de noviembre, el Consejo Real, pareciéndole muy justo su proceder, ordenó a los prelados por medio de una real cédula que sin dilación llevasen a efecto la visita y corrección de los cabildos. En ella se argumentaba tal decisión de la siguiente manera: los cabidos por todas las vías y maneras intentan impedir el buen efecto de los decretos conciliares $y$, desvirtuando la verdad, han conseguido breves y letras apostólicas por las cuales se anula todo lo hecho por los obispos en la observancia del decreto tri-

36 ACB, carta del cardenal del Monte al nuncio, 14 de septiembre de 1554. En esta época era presidente del Consejo Real Antonio Fonseca, anteriormente obispo de Pamplona. 
dentino; por ello se informa al papa de la conveniencia de la observancia del mencionado decreto, con la seguridad de que una vez bien informado tendrá a bien que se cumpla lo establecido en Trento, y se mande a los obispos sigan adelante en la visita y corrección de sus capitulares ${ }^{37}$.

Por medio de la correspondencia del cabildo de Burgos llegaron a Roma noticias alarmantes de una nueva intervención de la justicia civil:

«...por letras de los señores del cabildo de Burgos tengo aviso que los señores del Consejo han despachado un alcalde de corte para Burgos, y para otras iglesias otros jueces, sin haber habido más delictos que solamente haber hecho las intimaciones del breve de los prelados, lo cual me ha dado demasiada pena ${ }^{38}$.

Los canónigos burgaleses diputados para actuar en este enojoso pleito, y autores de la fijación del documento pontificio en las puertas de la catedral, fueron confinados en Aranda de Portugal. Con los prebendados de Zamora también descargó su furia el Consejo Real, que desterró a varios de ellos. Además del extrañamiento, se recurrió a la confiscación de bienes de los rebeldes, entre los que también se incluyó a Castrillo. El argumento principal esgrimido por el Consejo para justificar los destierros de los capitulares consistía en considerar un desacato contra el papa y nuncio el cometido por éstos al fijar los breves.

El nuncio intercedió ante el Consejo Real para que fueran levantadas las penas, pues así se lo manifestó a Castrillo: «En lo que toca a los desterrados de Burgos y de Zamora, pierda vuestra merced cuidado que yo he tomado este cargo de solicitar por su reducción, y ya el presidente me tiene dada intención de revocallo, y hoy seré con él y no afloxaré hasta que vuelvan a su iglesia» ${ }^{39}$.

Esta singular lucha tenía varios frentes: cabildos exentos, obispos reformadores, nuncio de su Santidad, Carlos I, a la sazón en Alemania, Felipe II, que se encontraba en Inglaterra, doña Juana, Princesa Gobernadora $y$, por último Roma. No es de extrañar que se complicaran las cosas, hasta el punto de no saberse con claridad qué estaba ocurriendo en todos los lugares en un momento determinado, dando ocasión a noticias contradictorias. Tal era el caso del emperador Carlos $\mathrm{V}$, de quien

7 Caballero F., op. cit., vol. 2, págs. 493 y sigs.

38 Ibidem, carta de Castrillo al cabildo de Burgos, 16 de diciembre de 1554.

39 Ibidem, carta del nuncio a Castrillo, 8 de enero de 1555; carta de Castrillo a su cabildo, 14 de enero de 1555. Cfr. López, N., op. cit, pág. 16, nota 69 , donde se recogen los nombres de los 5 prebendados que fueron desterrados. 
llegaba un despacho ordenado que se cumpliesen los breves, a la vez que se confirmaba su intercesión al romano pontífice para que fuesen revocados.

Mientras tanto, no se dormía el Consejo Real, que envió un memorial al papa con objeto de persuadirle de la conveniencia de revocar los enérgicos breves, alegando la corrupción de los capitulares y, por tanto, la necesidad de la corrección y castigo de los culpables. Castrillo, con su gracejo acostumbrado, aclara el quid de la cuestión:

«.. y dando a entender largamente la mala vida que los clérigos de esos reinos hacemos, y lo mucho que conviene seamos corregidos y castigados. $Y$ esto viene con tanto calor que muestran bien los señores prelados, que es de pensar que son los que procuran esto, cuánta voluntad tienen de salir con su intención; la cuál, así su Santidad como estos señores reverendísimos diputados, creo tienen bien entendida. Y aunque el dicho memorial es harto largo, se podría replicar del concluyentemente con una palabra, y es que nosotros no pretendemos no ser castigados, sino la forma de cómo ha de ser; aunque a esto responden por el dicho memorial que se hace justicia como entre compadres. A esto está replicado, y los señores que han de declarar tan bien entendido que ni permitirán que nosotros seamos viçiosos, ni sus señorías tan patrones, que sólo penda nuestra justicia y autoridad de su voluntad ${ }^{40}$.

Los últimos acontecimientos provocaron un nuevo proceder: el envío por el papa Antonio Agustín como interlocutor ante Carlos I y Felipe II, pero su misión no parece que tuvo éxito apreciable.

El procurador burgalés consiguió otro breve que remitió a Burgos el 30 de enero de 1555, que iba dirigido a la princesa doña Juana, reina de Portugal y gobernadora de España por ausencia de su hermano Felipe II, la cual siempre había mostrado buena disposición hacia la Sede Apostólica. En el texto del documento, según el sagaz Castrillo, iba una declaración muy sutil:

«...y declarar que tiene por descomulgados a los que no han obedecido, aunque debaxo de hartas y cubiertas palabras, lo cual no es posible no haga resentir las conciencias de los señores a quien toca» ${ }^{41}$.

El Consejo Real por estas fechas decidió hacer una consulta a los dos teólogos más eminentes del momento, los dominicos Melchor Cano y

40 Ibidem, carta de Castrillo al cabildo de Burgos, 22 de febrero de 1555.

41 Ibidem, cartas de Castrillo al cabildo de Burgos, 14, 19 y 30 de enero de 1555. 
Domingo de Soto. Éstos emitieron un parecer en el que, haciendo gala de sutilezas argumentales, se mostraron excesivamente condescendientes, hasta el punto de justificar abusos propios de la política regalista de la época ${ }^{42}$.

Tanto los obispos como los canónigos sabían que la clave para ganar esta batalla era la reforma proyectada que pensaba publicar el papa, por este motivo ambos bandos centraron su atención en la comisión de cardenales encargarda de llevarla a cabo, a la vez que buscaban con ahínco defensores de sus derechos, pero la muerte de Julio III abortó esta vía.

Las espadas quedaban en alto, y tanto lo capitulares como los prelados tendrían que redoblar sus esfuerzos para inclinar la balanza a su favor. Efectivamente, será en el pontificado de Paulo IV cuando se recrudezca la contienda, enredándose con las tensas relaciones entre el papa y Felipe II, que desembocó en una absurda guerra. En la tercera convocatoria del concilio de Trento se llegó a una solución de compromiso con cesiones por ambas partes.

42 Caballero, F., op. cit. vol. 2, págs. 493 y sigs. 